\title{
Correction to: Speciation of carboxylic components in humic-like substances (HULIS) and source apportionment of HULIS in ambient fine aerosols $\left(\mathrm{PM}_{2.5}\right)$ collected in Hong Kong
}

\author{
Yiqiu Ma ${ }^{1} \cdot$ Yubo Cheng ${ }^{1} \cdot \mathrm{Gang} \mathrm{Cao}^{2} \cdot \operatorname{Jian} \mathrm{Zhen} \mathrm{Yu}^{3} \cdot \mathrm{Di} \mathrm{Hu}^{1,4}$ \\ Published online: 27 May 2020 \\ (C) Springer-Verlag GmbH Germany, part of Springer Nature 2020
}

\section{Correction to: Environmental Science and Pollution Research} https://doi.org/10.1007/s11356-020-08915-w

The correct name of the $3^{\text {rd }}$ Author is presented in this paper.

Publisher's note Springer Nature remains neutral with regard to jurisdictional claims in published maps and institutional affiliations.

The online version of the original article can be found at https://doi.org/ 10.1007/s11356-020-08915-w

Di Hu

dihu@hkbu.edu.hk

1 State Key Laboratory of Environmental and Biological Analysis, Department of Chemistry, Hong Kong Baptist University, Hong Kong SAR, People's Republic of China

2 School of Civil and Environmental Engineering, Harbin Institute of Technology Shenzhen Graduate School, Shenzhen 518055, People's Republic of China

3 Department of Chemistry, Hong Kong University of Science and Technology, Clear Water Bay, Hong Kong SAR, People's Republic of China

4 HKBU Institute of Research and Continuing Education, Shenzhen Virtual University Park, Shenzhen 518057, People's Republic of China 